\title{
TNF expressed by tumor-associated macrophages, but not microglia, can eliminate glioma
}

\author{
JIRO NAKAGAWA ${ }^{1,2}$, MASANAO SAIO ${ }^{2}$, NORIYUKI TAMAKAWA ${ }^{1,2}$, \\ TATSUHIKO SUWA ${ }^{2}$, ALAN B. FREY ${ }^{5}$, KENICHI NONAKA ${ }^{2,3}$, NAOKI UMEMURA ${ }^{2,4}$, \\ HISASHI IMAI ${ }^{2,3}$, GUAN-FENG OUYANG ${ }^{2}$, NAOYUKI OHE ${ }^{1}$, HIROHITO YANO ${ }^{1}$, \\ SINICHI YOSHIMURA ${ }^{1}$, TORU IWAMA ${ }^{1}$ and TSUYOSHI TAKAMI ${ }^{2}$
}

\begin{abstract}
Departments of ${ }^{1}$ Neurosurgery, ${ }^{2}$ Imunopathology, ${ }^{3}$ Oral and Maxillofacial Sciences, ${ }^{4}$ Surgical Oncology, Gifu University Graduate School of Medicine, 1-1 Yanagido, Gifu, Japan; ${ }^{5}$ Department of Cell Biology, New York University School of Medicine, 550 First Avenue, New York, NY 10016-6042, USA
\end{abstract}

Received November 8, 2006; Accepted December 20, 2006

\begin{abstract}
It is well known that tumor necrosis factor (TNF) can have both contrary and pleiotropic effects in anti-tumor immune response. In the present study, we prepared two different tumor cell-based immunotherapy models: MCA38 adenocarcinoma and GL261 glioma intracranial interleukin-2 (IL-2)-based. Each tumor was transfected to express IL-2 with or without expression of the soluble form of tumor necrosis factor receptor type II (sTNFRII). Although mice in which TNF is blocked survive longer than IL-2 alone (35.2 versus 26 days), the reverse was observed for GL261 glioma. The differential effect on tumor growth implies enhanced TNF sensitivity of GL261 compared to MCA38. This notion is supported by the observation that TNF induces apoptosis in GL261 but not MCA38 tumors. We further examined tumor infiltrating $\mathrm{CD} 11 \mathrm{~b}^{+} \mathrm{F} 4 / 80^{+}$macrophages (or tumor-associated macrophages: TAM) for TNF production in vivo and found that TAM express cell surface TNF implying a role in eliminating glioma cells mediated by the cell surface form of TNF.
\end{abstract}

\section{Introduction}

Malignant glioma is well known as having one of the worst prognosis $(1,2)$. Several experimental immunotherapy models (1) and clinical trials $(2,3)$ have been attempted, emphasizing patients with tumor recurrence $(4,5)$. Current therapy consists of surgical resection, radiation, and chemotherapy but are, in general, palliative and a new treatment modality is needed.

Correspondence to: Dr Masanao Saio, Department of Immunopathology, Gifu University Graduate School of Medicine, 1-1 Yanagido, Gifu, Gifu 501-1194, Japan

E-mail: saio@gifu-u.ac.jp

Key words: tumor-associated macrophages, microglia, tumor necrosis factor, interleukin-2 tumor immunity, central nervous system
Typically tumor immunotherapy has fewer adverse effects in comparison to radiation or chemotherapy (5); however, the mechanism of tumor clearance by the immune response is complicated, and the mechanism in vivo is also poorly understood. For example, in analyses of human tumors, the relation between tumor-associated macrophages (TAM) and clinical prognosis is uncertain. That is, in some studies TAM infiltration into tumors indicates a worse prognosis (e.g. breast cancer, prostate cancer, endometrial carcinoma, bladder cancer, and renal cell carcinoma) but TAM infiltration is associated with better prognosis in other tumor types (e.g. gastric cancer, colon cancer, and melanoma) (6). This variability may mean that macrophage association with cancer progression may vary being dependent on the origin of the tumor cells.

Tumor necrosis factor (TNF) is a well known pleiotropic cytokine that induces cell invasion (7), direct induction of tumor cell death (8), and indirect induction of tumor cell death by activating anti-tumor immunity (9). The TNF receptor (TNFR) is composed of two different types: the Type I receptor (CD120a) and the Type II receptor (CD120b), which regulate differential responses to TNF signaling $(8,10)$. CD120a signaling results in cell death via apoptosis induction and CD120b signaling induces cell survival via induction of nuclear factor $\mathrm{\kappa B}(8,10)$. In addition, TNF signaling in myeloid cells can result in expression of nitric oxide that in turn can mediate apoptosis of proximal cells, including immune cells (11). Thus, TNF can positively or negatively regulate immune responses depending on the context. Because of its pivotal role in immune response, it is important to analyze whether TNF is positively or negatively associated in immunotherapy.

In the present study, we prepared two different murine tumor cell models; MCA38 adenocarcinoma and GL261 glioma that express interleukin-2 (IL-2). Injection of these modified tumor cells results in enhanced priming of anti-tumor immune responses and delay of tumor growth compared to wild-type tumor. In order to study the role of TNF signaling in a therapeutic modality, we also expressed the soluble form of CD120b in either wild-type or IL-2-expressing tumor cells. The soluble TNF receptor acts as a 'sink' for TNF and effectively blocks the action of TNF in the tumor microenvironment. 
Using these modified tumor cell lines, we analyzed the importance of TNF in a model of immunotherapy.

\section{Materials and methods}

Mice. Male C57BL/6 (B6) mice, 6-8 weeks old, were purchased from SLC (Wilmington, MA, USA). The mice were maintained in accordance with the guidelines of the Committee on Animals of Gifu University School of Medicine.

Cell lines. Murine colon carcinoma cell line, MCA38 was originally provided by Dr Yang Liu (Ohio State University, Columbus, OH). Murine glioma cell line GL261 was originally provided by Dr Elizabeth Newcomb (Department of Pathology, New York University School of Medicine, New York, NY). Tumor cells were cultured in RPMI-1640 medium or D-MEM (Invitrogen Life Technologies, Carlsbad, CA) containing 10\% fetal calf serum (FCS), L-glutamate (Invitrogen Life Technologies), and penicillin-streptomycin (Invitrogen Life Technologies). The cells were maintained at $37^{\circ} \mathrm{C}$ in a humidified $5 \% \mathrm{CO}_{2}$ atmosphere. Murine TNF receptor type II (TNFRII) and IL-2 cDNA or vector vehicle alone was transferred into the MCA38-wild-type cells (MCA38-wt) or GL261-wild-type cells (GL261-wt) as described below.

cDNA preparation and plasmid construction. Naïve spleen cells were prepared from normal B6 mice, and stimulated with $1 \mathrm{nM}$ phorbol miristate 13 acetate (Sigma, St. Louis, MO) and $1 \mathrm{nM}$ calcium ionophore (Sigma) in complete RPMI-1640 medium for $12 \mathrm{~h}$. Total RNA was prepared by ISOGEN (Nippon Gene, Tokyo, Japan), and then reverse-transcribed using M-MLV reverse-transcriptase (Invitrogen Life Technologies). cDNA was amplified with an Expanded Long Template PCR system ${ }^{\circledR}$ (Roche Diagnostics, Mannheim, Germany). The primer pairs used to amplify the open reading frames of TNFRII and IL-2 were: TNFRII upper primer: 5'GAG CCA CCG CTG CCC CTA TG-3', TNFRII lower primer: 5'-TTC AAC CCA ACG ATG TAA GGA TGC-3', (underlined part was changed artificially to ' $\mathrm{C}$ ' from original sequence ' $G$ ' in order to create termination codon), IL-2 upper primer: 5'-CAG CCT TGC TAA TCA CTC CTC AC-3', IL-2 lower primer: 5'-GCG CTT ACT TTG TGC TGT CCT A-3'.

Transfection. The amplified cDNAs were cloned into pCR2.1 cloning vector (Invitrogen Life Technologies) expressed in JM109 E. coli (Takara, Seta, Japan), and plasmid DNA was purified with Qiagen-tip 500 (Qiagen, Hilden, Germany). The plasmid DNA containing an open reading frame of interest and vectors pcDNA3.1neo (Invitrogen Life Technologies) and pcDNA3.1hyg (Invitrogen Life Technologies) were digested with Bst-XI and isolated following agarose gel electrophoresis. The TNFRII or IL-2 cDNA fragments were inserted into vectors and purified. Recombinant plasmids were authenticated by restriction enzyme analyses, and introduced into MCA38-wt cells or GL261-wt cells by electroporation ('Cell-Porator', Life Technologies, Rockville, MD). Transfected cells were selected with $0.6 \mathrm{mg} / \mathrm{ml}$ of G418 (Invitrogen Life Technologies) for pcDNA3.1neo and $0.2 \mathrm{mg} / \mathrm{ml}$ of hygromycin (Invitrogen Life Technologies) for pcDNA3.1hyg. Then the limiting dilution method was employed to establish single cell derived cell
Table I. Level of IL-2 and soluble TNFRII in tumor cell supernatants.

\begin{tabular}{lcc}
\hline Cells $\left(1 \times 10^{6}\right.$ cells/ml $)$ & IL-2 $(\mathrm{ng} / \mathrm{ml})$ & sTNFRII $(\mathrm{ng} / \mathrm{ml})$ \\
\hline MCA38mock & $\mathrm{ND}$ & $\mathrm{ND}$ \\
MCA38sTNFR & $\mathrm{ND}$ & $5.16 \pm 0.144$ \\
MCA38IL-2 & $1.63 \pm 0.119$ & $\mathrm{ND}$ \\
MCA38IL-2/sTNFRII & $1.37 \pm 0.136$ & $5.26 \pm 0.537$ \\
GL261mock & $\mathrm{ND}$ & $\mathrm{ND}$ \\
GL261sTNFRII & $\mathrm{ND}$ & $5.10 \pm 0.561$ \\
GL261IL-2 & $3.55 \pm 0.599$ & $\mathrm{ND}$ \\
GL261IL-2/sTNFR & $3.03 \pm 0.697$ & $3.78 \pm 0.252$ \\
\hline
\end{tabular}

$\mathrm{ND}$, not detectable.

lines. We prepared sTNFRII inoculated MCA38 clone MCA38sTNFRII\#3 (MCAsTNFRII) or GL261 clone GL261sTNFRII\#3 (GL261sTNFRII). The level of sTNFRII secretion in MCAsTNFRII and GL261sTNFRII for $24 \mathrm{~h}$ cultured supernatant of $1 \times 10^{6}$ cells $/ \mathrm{ml}$ is summarized in Table I. Then we transfected the IL-2 cDNA into MCAmock, MCAsTNFRII, GL261mock, and GL261sTNFRII to obtain IL-2 secreting clones; MCA38IL-2\#75 (MCAIL-2) and GL261IL-2\#20 (GL261IL-2), and sTNFRII and IL-2 double secreting clone; MCA38IL-2/sTNFRII\#15 (MCAIL-2/ sTNFRII) and GL261IL-2/sTNFRII\#3-93 (GL261IL-2/ sTNFRII). Each cell line used in this study showed the same growth kinetics in vitro as the non-modified (wild-type) cells (data not shown). The levels of IL-2 secretion in each sub-line used in this study are summarized in Table I.

Implantation of tumor cells. All mice were anesthetized with an intramuscular injection of pentobarbiturate $(2.5 \mathrm{mg}$ / mouse; Dainippon-Sumitomo, Osaka, Japan). For intracranial implantation, $5 \times 10^{5}$ cells were stereotactically inoculated intracranially using a $10 \mu \mathrm{l}$ Hamilton syringe (Hamilton Company, Reno, NV). The site of the inoculation was $2 \mathrm{~mm}$ to the right of the midline, $2 \mathrm{~mm}$ posterior to the bregma, and $4 \mathrm{~mm}$ below the cranium. As a result of intracranial inoculation, tumor formations were observed in the parenchyma. In addition, neither extra-cranial nor subscalp tumor mass formation was observed. For subcutaneous (s.c.) and intrahepatic (i.h.) implantation, the same number of cells was inoculated into sub-capsule of liver or subcutaneous space of the left flank of mice.

Immunofluorochemical analysis. Fourteen days after tumor inoculation, mice were sacrificed. Tissue samples were collected and embedded with O.C.T. compound (Tissue Tek, Miles, Elkhart, IN) before freezing under liquid nitrogen. Sections $(4 \mu \mathrm{m})$ were cut using a cryostat then fixed with cold acetone for $10 \mathrm{~min}$. The specimen was pretreated with antiCD16/32 (2.4G2, $10 \mu \mathrm{g} / \mathrm{ml})$ (PharMingen, San Diego, CA), then reacted with FITC conjugated-rat anti-mouse CD11b (M1/70, $10 \mu \mathrm{g} / \mathrm{ml}$ ) (PharMingen) and PE conjugated-rat antimouse CCR3 $(10 \mu \mathrm{g} / \mathrm{ml})$ (R\&D Systems, Inc., Minneapolis, 

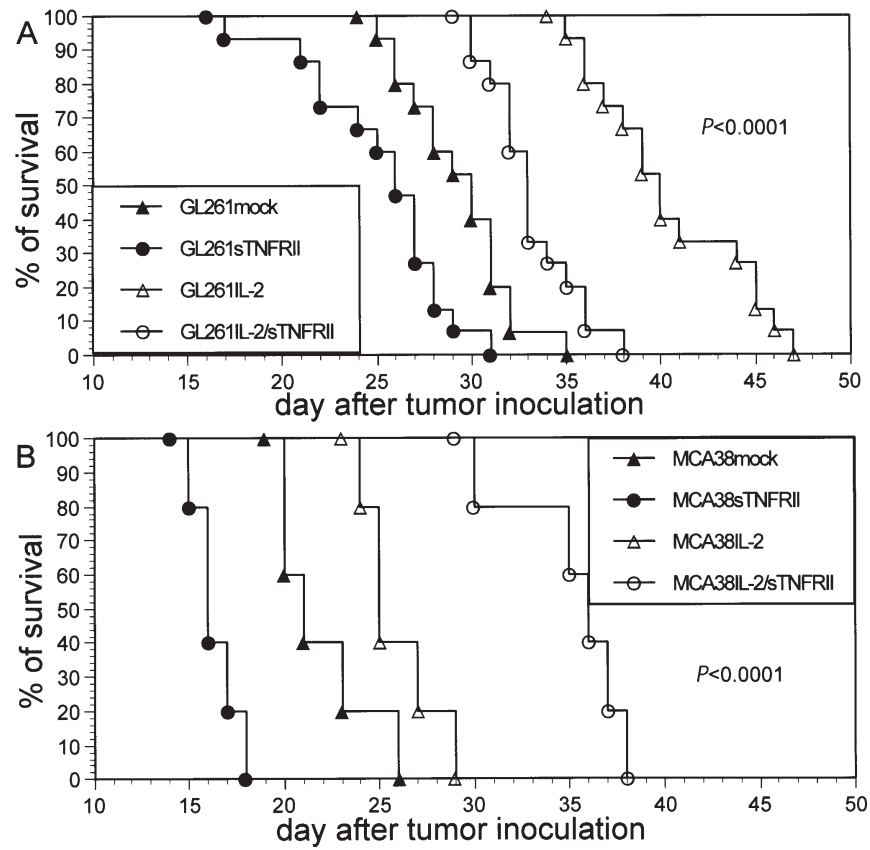

Figure 1. Survival curve of immunotherapy model. Tumor cells $\left(1 \times 10^{5}\right)$ were stereotactically inoculated into brain parenchyma and survival was observed until all mice were dead. Each statistical analysis was performed versus MCA/mock or GL261/mock tumor. In each group, 5 mice (for MCA38) or 15 mice (for GL261) were used.

MN). After washing 3 times with PBS, specimens were analyzed with a model DM RA Fluorescence microscope with QFISH ${ }^{\circledR}$ software (Leica Microsystems Imaging Solutions Ltd., Cambridge, UK).

Tumor infiltrating cell preparation. Mice were sacrificed 14 days after tumor implantation for analysis. Cell preparation was performed as described previously (11). In brief, each tumor was collected and minced into small pieces before incubation for $15 \mathrm{~min}$ at $37^{\circ} \mathrm{C}$ with a mixture of enzymes dissolved in HBSS [collagenase Type I $(0.05 \mathrm{mg} / \mathrm{ml})$, collagenase Type IV $(0.05 \mathrm{mg} / \mathrm{ml})$, hyaluronidase $(0.025 \mathrm{mg} / \mathrm{ml})$, all from Sigma, and DNase I $(0.01 \mathrm{mg} / \mathrm{ml})$ and soybean trypsin inhibitor $(0.2 \mathrm{TIU} / \mathrm{ml})$, both from Roche Diagnostics]. Digested cells were harvested and red blood cells lysed with hypotonic buffer $\left(0.155 \mathrm{M} \mathrm{NH}_{4} \mathrm{Cl}, 0.1 \mathrm{mM}\right.$ EDTA, $\left.10 \mathrm{mM} \mathrm{KHCO}_{3}\right)$ for $1 \mathrm{~min} . \mathrm{CD}_{11} \mathrm{~b}^{+}$and $\mathrm{CD} 8^{+}$cells were isolated by magnetic immunobeading using type $\mathrm{MS}^{+}$or $\mathrm{LS}^{+}$columns according to the manufacturer's instructions (MACS, Miltenyi Biotec, Berdish-Gladbach, Germany). In brief, $10 \mu 1$ of anti-CD11b or anti-CD8a magnetic bead suspension (Miltenyi Biotec) was added to $10^{7}$ cells in a final volume of $0.1 \mathrm{ml}$ cold HBSS containing $0.5 \% \mathrm{BSA}$. After incubation for $15 \mathrm{~min}$, cells were washed and passed through a separation column. The columnbinding population was collected as the $\mathrm{CD} 11 \mathrm{~b}^{+}$or $\mathrm{CD}^{+}$cell fraction.

Flow cytometric analysis. All cells for flow cytometric analysis were pre-incubated with $10 \mu \mathrm{g} / \mathrm{ml}$ of anti-CD16/32 antibody (2.4G2, PharMingen) at $4^{\circ} \mathrm{C}$ for 30 min before staining with specific antibodies. For $\mathrm{CD}_{1} 1 \mathrm{~b}^{+}$cell surface antigen expression analysis, allophycocyanin (APC)-conjugated anti-CD11b
Table II. ELISA of TNF $\alpha$ and IFN $\gamma$ expressed by GL261 tumor-infiltrated CD11 $\mathrm{b}^{+}$cells.

Cytokines Cells recovered from Concentration (ng/ml)

\begin{tabular}{lll}
\hline IFN $\gamma$ & GL261 mock & ND \\
& GL261IL-2 & ND \\
TNF $\alpha$ & GL261mock & ND \\
& GL261IL-2 & ND \\
\hline
\end{tabular}

Cells $\left(3 \times 10^{6}\right)$ of each $\mathrm{CD} 11 \mathrm{~b}^{+}$population were cultured for $24 \mathrm{~h}$ before submitted for analysis. Sensitivity of assay is $1.56 \mathrm{ng} / \mathrm{ml}$ for IFN $\gamma$ and $3.125 \mathrm{ng} / \mathrm{ml}$ for TNF $\alpha$. ND, not detectable.

(10 $\mu \mathrm{g} / \mathrm{ml}, \mathrm{M} 1 / 70$, PharMingen), and FITC-conjugated anti$\mathrm{F} 4 / 80(10 \mu \mathrm{g} / \mathrm{ml})$ were utilized for all staining. Anti-TNF $\alpha$ (10 $\mu \mathrm{g} / \mathrm{ml}$, MP6-XT22, PharMingen), anti-CD25 (10 $\mu \mathrm{g} / \mathrm{ml}$, PC61, PharMingen), anti-CD122 (10 $\mu \mathrm{g} / \mathrm{ml}$, TM- 31 , PharMingen), anti-CD132 (10 $\mu \mathrm{g} / \mathrm{ml}, 4 \mathrm{G} 3$, PharMingen), anti-CD45 (10 $\mu \mathrm{g} / \mathrm{ml}, 30 \mathrm{~F} 11$, PharMingen), anti-CCR3 (10 $\mu \mathrm{g} /$ $\mathrm{ml}$, clone \#83101, R\&D), anti-CD120a (10 $\mu \mathrm{g} / \mathrm{ml}$, HM104, Serotec Ltd., Oxford, UK), anti-CD120b (10 $\mu \mathrm{g} / \mathrm{ml}, \mathrm{HM102}$, Serotec Ltd.) control rat IgG1 (10 $\mu \mathrm{g} / \mathrm{ml}$, PharMingen), rat IgG2a $(10 \mu \mathrm{g} / \mathrm{ml}$, PharMingen, and Serotec Ltd.), and rat IgG2b (10 $\mu \mathrm{g} / \mathrm{ml}$, PharMingen) were utilized as PE-conjugated antibodies. Cells were incubated with antibodies for $30 \mathrm{~min}$ at $4^{\circ} \mathrm{C}$. After washing with PBS, cells were fixed with $1 \%$ paraformaldehyde/PBS, before analysis using a FACS ${ }^{\circledR}$ Calibur flow cytometer and Cell Quest software (Becton Dickinson Japan, Tokyo).

Polymerase chain reaction. Total RNA was prepared using the Trizol reagent (Invitrogen). Total RNA (600 ng) was utilized for reverse-transcription reactions with Superscript III reversetranscriptase (Invitrogen). Reactions were performed following the protocol provided by the manufacturer. Primer pair mixture, buffer, and Taq polymerase that were provided as part of kit (MPCR kit for mouse chemokine gene set-1, MPCR kit for mouse chemokine receptors CCR set-1, set-2, and MPCR kit for mouse inflammatory cytokine gene set-1, Maxim Biotech, Inc., South San Francisco, CA) and 100 ng of sample cDNA or provided positive control DNA mixture were mixed and polymerase chain reaction was performed following the condition provided in the manufacturer's instruction manual. Amplified DNA was analyzed by $5 \%$ acrylamide gel electrophoresis followed by ethidium bromide staining.

Apoptosis analysis. Tumor cells $\left(1 \times 10^{6}\right.$ cells/well in 24-well plate) were treated with interferon $\gamma(\operatorname{IFN} \gamma)$ alone $(100 \mathrm{ng} / \mathrm{ml})$, TNF alone (final $100 \mathrm{ng} / \mathrm{ml}$ ) or a combination of IFN $\gamma$ and TNF for $24 \mathrm{~h}$, and cells were recovered by treatment with Dispase (Invitrogen Corp., $300 \mathrm{U} / \mathrm{ml}$ for $30 \mathrm{~min}$ ). After washing with Annexin binding buffer (0.01M HEPES, $0.14 \mathrm{M} \mathrm{NaCl}, 2.5 \mathrm{mM}$ $\mathrm{CaCl}_{2}, \mathrm{pH}$ 7.4), the cells were stained with PE-conjugated Annexin $\mathrm{V}$ and Via-probe (both from PharMingen) for $15 \mathrm{~min}$ at $4^{\circ} \mathrm{C}$. After washing with Annexin binding buffer, the cells were analyzed by flow cytometry. 
A
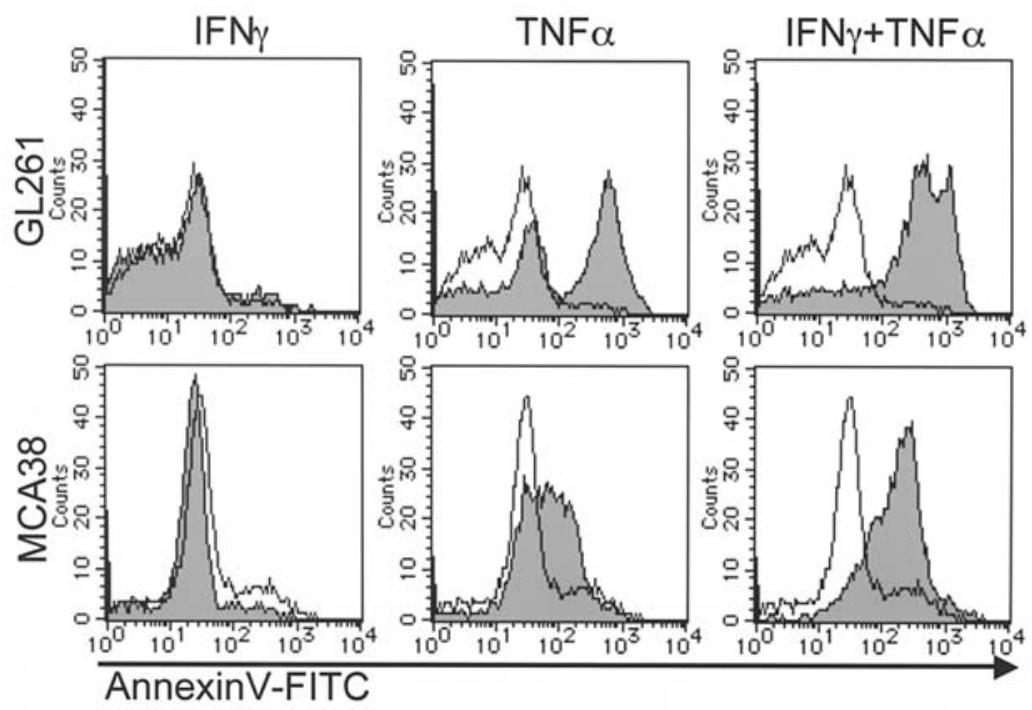

B

cont.
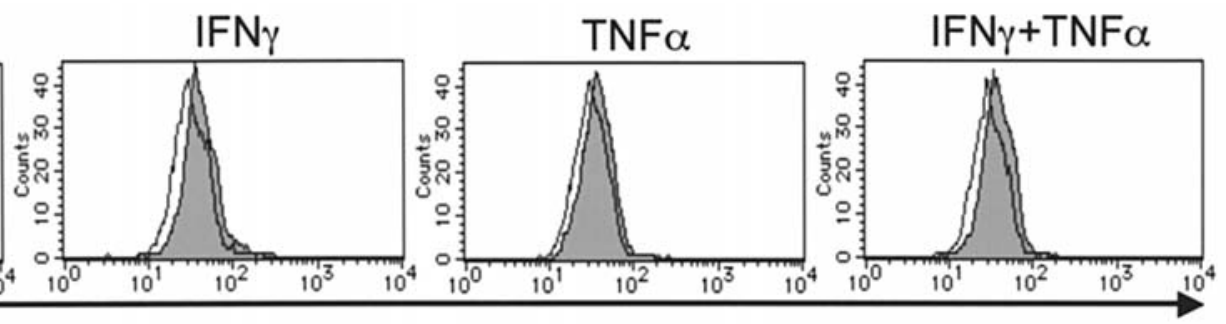

CD120a-PE


CD120b-PE

Figure 2. Flow cytometric analysis of apoptosis in MCA38 and GL261 cells (A) and TNF receptor expressions in GL261 (B) after treatment with cytokines in vitro. Tumor cells were analyzed $24 \mathrm{~h}$ after cytokine treatment $(100 \mathrm{ng} / \mathrm{ml}$ each). Representative data out of 2 independent experiments are demonstrated.

Statistics. For statistical analysis, we used the Kaplan-Meier survival test with the log rank test to evaluate tumor-free survival. In the other cases, we used the Student's t-test. p-values $<0.05$ were considered statistically significant.

\section{Results}

Differential effect of immunotherapy is dependent on the tumor cell type. We established vector-modified tumor cell lines MCA38 and GL261 to use in immunotherapy experiments: alone (mock), transfected with IL-2 cDNA (IL-2), transfected with sTNFRII cDNA (sTNFRII), or IL-2 and sTNFRII simultaneously (IL-2/sTNFRII). cDNA transfection did not affect the growth rate of the cell lines in vitro (data not shown). The amount of IL-2 or sTNFRII produced from the each sub-line is summarized in Table I. Next, we investigated the in vivo growth rate of the different tumor cell lines. As shown in Fig. 1, TNF blocking alone in MCA38 adenocarcinoma (MCAsTNFRII) shortened the survival of mice in comparison to MCAmock (wild-type), while expression of soluble TNF Receptor combined with expression of IL-2
(MCAIL-2/sTNFRII) elongated survival of mice in comparison to IL-2 single transfected MCA-IL-2 inoculated mice. On the other hand, in the glioma model TNF blocking plus IL-2 expression shortened the survival of mice in comparison to expression of IL-2 alone. These data suggest that TNF blocking can inhibit or restrict anti-tumor immune response, an effect especially pronounced in the GL261 tumor model.

TNF induced apoptosis in GL261 glioma cells but not in MCA38 adenocarcinoma cells. Based on the differential effect of TNF blockade in the different tumor types, we hypothesized that GL261 and MCA38 tumors may display disparate sensitivity to TNF. We asked if TNF affected either tumor cell growth rate or survival in vitro. As shown in Fig. 2A, treatment of wild-type tumor cells with TNF alone for $24 \mathrm{~h}$ induced GL261 apoptosis. However, MCA38 was resistant to TNF treatment. In addition, combination of IFN $\gamma$ and TNF increased apoptosis of both GL261 and MCA38 cells. We further examined TNF receptor expression on GL261 cells. Interestingly, not TNF treatment but IFN $\gamma$ treatment enhanced the expression of both CD120a and CD120b on GL261 cells 



Figure 3. Flow cytometric analysis of cell surface TNF expression on CNS tumor infiltrating CD11 $\mathrm{b}^{+}$cells. CD11 $\mathrm{b}^{+}$cells were isolated on day 14 after tumor inoculation and analyzed for expression of surface TNF (Pro-TNF). Representative histograms from at least 2 separate experiments are shown.
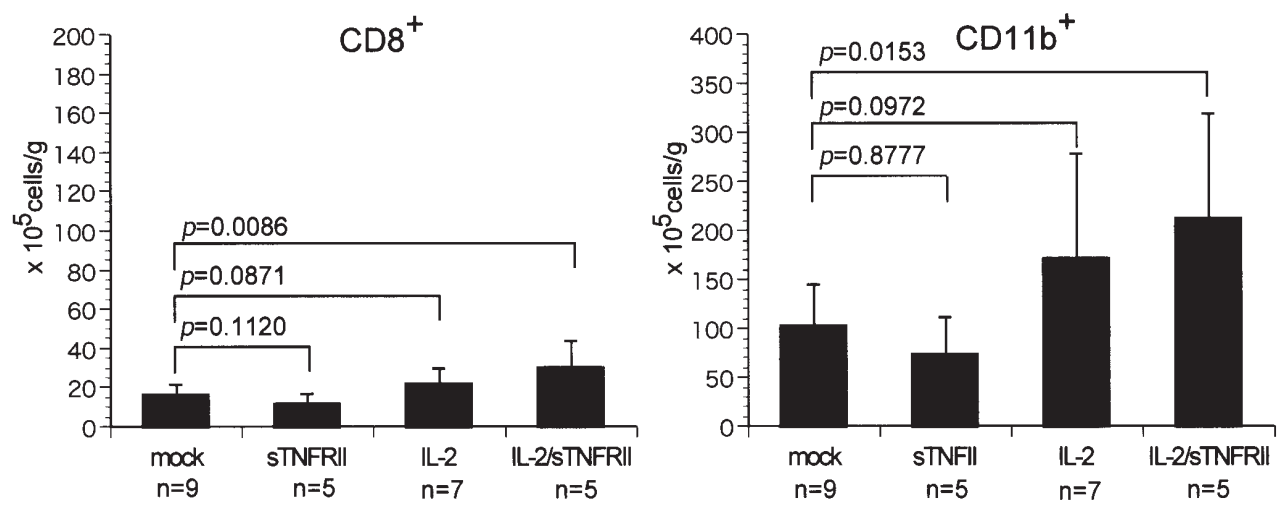

Figure 4. The number of tumor-infiltrating CD8 $8^{+}$cells and CD11 $\mathrm{b}^{+}$cells in GL261 tumor tissue. $1 \times 10^{5}$ tumor cells were stereotactically inoculated into brain parenchyma and $\mathrm{CD} 8^{+}$or $\mathrm{CD} 11 \mathrm{~b}^{+}$cells were recovered, then the recovered cells per gram of tumor tissue were calculated. Each statistical analysis was performed versus mock tumor. ( $\mathrm{N}=5$ for each group).

(Fig. 2B). Therefore, these findings suggest that IFN $\gamma$ augmented TNF receptor expression on GL261 made tumor cells more susceptible to TNF induced apoptosis.

Tumor infiltrating $C D 11 b^{+}$cells express cell surface TNF but do not secrete TNF. In order to analyze TNF production in tumor infiltrating $\mathrm{CD}_{11} \mathrm{~b}^{+}$cells, we isolated tumor infiltrating CD11 $\mathrm{b}^{+}$cells from GL261 tumors (by magnetic immunobeading) and analyzed cultured cell supernatants by ELISA. As shown in Table II, the concentration of TNF (and IFN $\gamma$ ) was below the detectable level. Therefore, we checked the expression level of Pro-TNF on CD11 $b^{+}$cells. CD11b cells recovered from all conditions robustly expressed Pro-TNF on the cell surface (Fig. 3). These data suggest that TNF produced from $\mathrm{CD}_{1} 1 \mathrm{~b}^{+}$cells is not released from the cell surface, at least under our conditions of analysis in vitro. We further analyzed expression of other cell surface molecules on CD11 $\mathrm{b}^{+}$ cells. However, there were no significant differences observed in levels of CD95, CD95L, CD120a, and CD120b from each cell line (data not shown).
Both T-cell and CD11 $b^{+}$cell infiltration is increased with IL-2 immunotherapy in intracranial GL261 tumors. Since we did not observe a strong increase in tumor growth in any GL261 sub-lines after depletion of T-cells or NK cells (using either anti-CD8a, anti-CD4, or anti-NK1.1 antibody, data not shown), we hypothesized infiltration of $\mathrm{CD}_{11} \mathrm{~b}^{+}$cells would be increased in vivo in GL261IL-2. We observed how many cells were infiltrated at the tumor site. Infiltration of not only $\mathrm{CD}^{+}$tumor infiltrating lymphocyte (TIL) but also CD11 $\mathrm{b}^{+}$ cells in GL261IL-2 were slightly increased $(P=0.0871$ for CD8 ${ }^{+}$T-cells, $P=0.0972$ for CD11b cells). In GL261IL-2/ sTNFRII, infiltration of both cell types significantly increased in comparison to the cells in GL261 mock ( $P=0.0086$ for $\mathrm{CD}^{+}$T-cells, $P=0.0153$ for $\mathrm{CD} 11 \mathrm{~b}^{+}$cells) (Fig. 4) although tumors did not regress as shown in Fig. 1. We have confirmed increased infiltration of CD8 ${ }^{+}$cells and CD11+ cells at the tumor site in GL261IL-2 and GL261IL-2/ sTNFRII by immunofluorescence analysis (data not shown).

We further examined the IL-2 receptor subunit expression pattern in CD11 b cells. In Fig. 5, we show two patterns of 

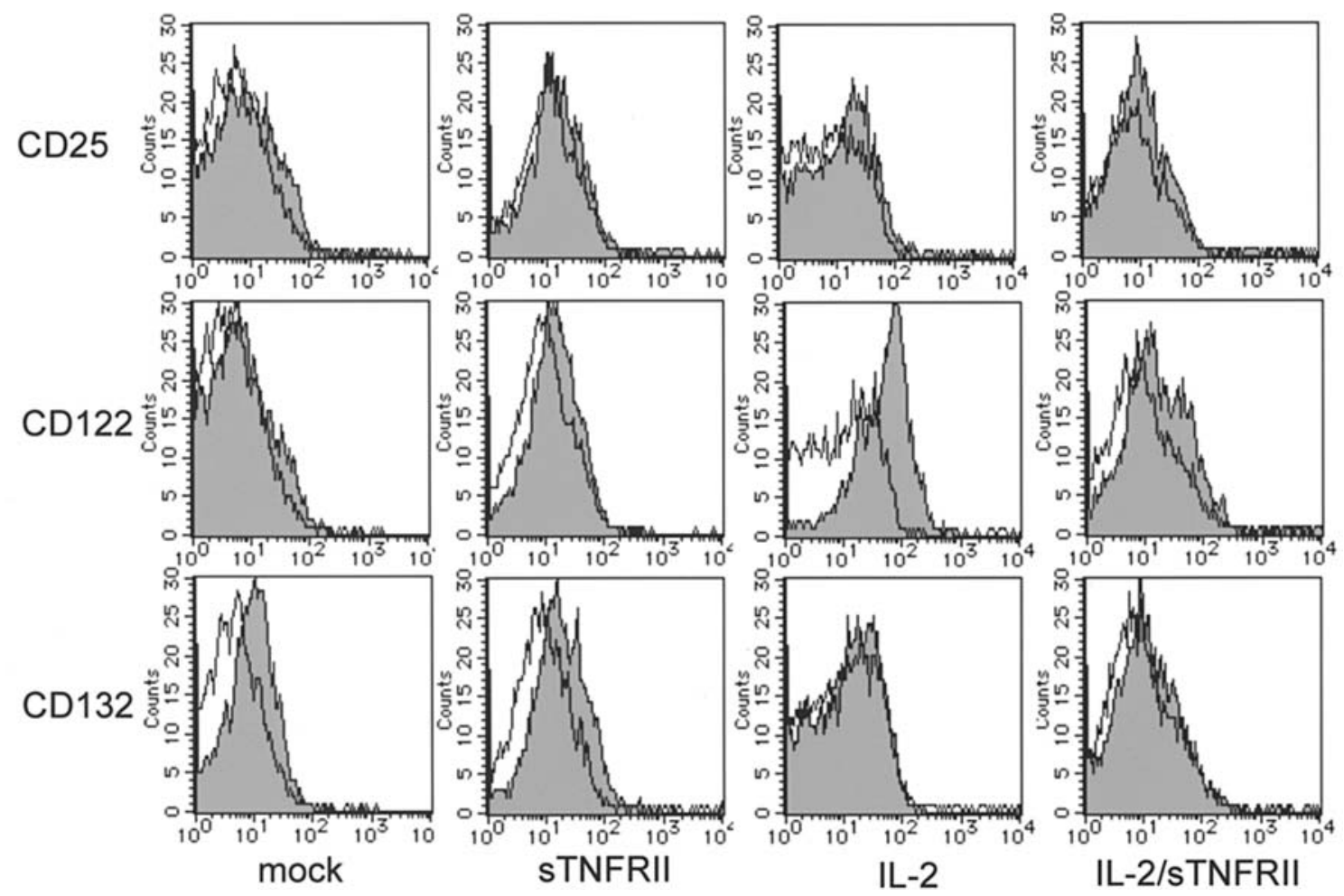

Figure 5. Flow cytometric analysis of IL-2 receptor subset expression on CD11 b tumor infiltrating cells recovered from day 14 after intracranial tumor inoculation. Each experiment was performed at least 5 times. Although both high affinity receptor $\left(\mathrm{CD} 25^{+} \mathrm{CD} 122^{+} \mathrm{CD} 132^{+}\right)$and $\mathrm{pseudo-high}$ affinity receptor $\left(\mathrm{CD} 25^{+} \mathrm{CD} 122^{+}\right)$patterns were observed in each group, a representative high affinity receptor pattern is shown in GL261mock and GL261sTNFRII, and a representative pseudo-high affinity receptor pattern is shown in GL261IL-2 and GL261IL-2/sTNFRII.

IL-2 subunit expression observed in each group, in some case (at least 5 independent experiments for each group), IL-2 subunits were composed of CD $25^{+} \mathrm{CD} 122^{+} \mathrm{CD} 132^{+}$high affinity type receptor although occasionally $\mathrm{CD} 25^{+} \mathrm{CD} 122^{+}$ CD132- pseudo-high affinity type receptors were observed. However, we could not find any fixed subunit expression pattern corresponding to a given tumor sub-line. These data suggest that increased infiltration of CD $11 b^{+}$cells in GL261IL-2 is not related to the subunit expression pattern of IL-2 receptors.

Expression pattern of cytokine, chemokine, and chemokine

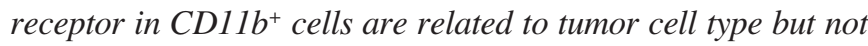
strongly related with tumor inoculated organs. In order to clarify the origin of $\mathrm{CD}_{1} 1 \mathrm{~b}^{+}$tumor infiltrating cells in the CNS, we inoculated the same tumor cells into brain, skin, and liver, and then the recovered $\mathrm{CD} 11 \mathrm{~b}^{+}$cells were compared for the expression pattern of cytokines, chemokines, chemokine receptors by multiple PCR. As shown in Fig. 6, the expression pattern of these molecules is related with tumor cell type. However, the pattern was not strongly related with the tumor inoculated organ. These data suggest that CD11 $\mathrm{b}^{+}$ tumor infiltrating cells may be derived from the same infiltrating cell type.

Majority of tumor infiltrating $\mathrm{CD} 11 b^{+}$cells are tumorassociated macrophages but not microglia. We clarified the expression of CCR3 and CD45 on CD11 b tumor infiltrating cells recovered from GL261mock. As shown in Fig. 7A and $\mathrm{B}, \mathrm{CCR} 3$ was expressed on the surface of $\mathrm{F} 4 / 80^{+}$cells recovered from normal brain and liver. However, $\mathrm{CCR}^{+}$cells were $<5 \%$ of $\mathrm{CD}_{1} 1 \mathrm{~b}^{+}$tumor infiltrating cells. In addition, CD45 was highly expressed on the CD11 $\mathrm{b}^{+}$tumor infiltrating cells. These data indicate that the majority of $\mathrm{CD} 11 \mathrm{~b}^{+}$tumor infiltrating cells classified to TAM (CCR3-CD45 ${ }^{\text {high }}$ ) but not microglia $\left(\mathrm{CCR} 3^{+} \mathrm{CD} 45^{+}\right)$.

Tumor expression of $I L-2$ did not alter the composition of $C D 11 b^{+}$tumor infiltrating cells. We clarified whether or not IL-2 therapy could induce microglia activation and alter the composition of $\mathrm{CD}_{11} \mathrm{~b}^{+}$tumor infiltrating cells to emphasize microglia. As shown in Fig. 8A, the cytokine, chemokine, and chemokine receptor expression patterns were not affected by tumor-elaborated IL-2. We did detect CCR3 ${ }^{+}$ $\mathrm{CD} 11 \mathrm{~b}^{+}$cells at the tumor site of GL261IL-2. However, the

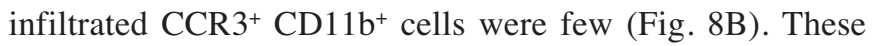
data suggest that IL-2 therapy did not induce microglia infiltration into the tumor site.

\section{Discussion}

In the tumor environment, macrophages are the largest population among tumor infiltrating immune cells (12). In the progression of human cancer, TAM are associated with several properties that favor tumor growth enhanced: 1) tumor invasion, 2) tumor growth, 3) tumor angiogenesis, 4) metastasis formation, and 5) immune suppression (6). According to 'the macrophage balance hypothesis' proposed by Mantovani et al, 

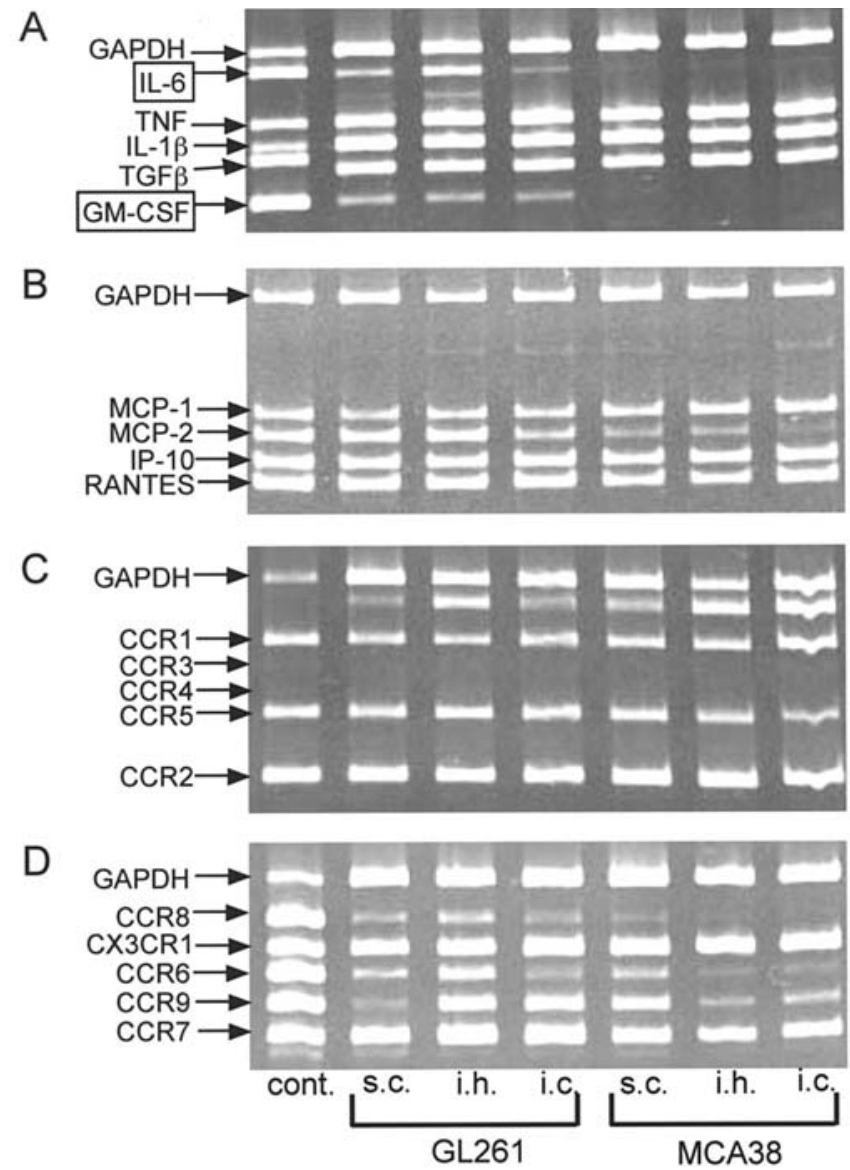

Figure 6. Multiple PCR analysis of cytokine, chemokine, and chemokine receptors. Total RNA from $\mathrm{CD} 11 \mathrm{~b}^{+}$tumor infiltrating cells recovered from GL261 mock or MCA38mock inoculated in brain (i.c.), liver (i.h.), and subcutaneous space (s.c.) were prepared and reverse transcription was performed. Then multiple PCR was performed and the samples were analyzed by $5 \%$ polyacrylamide gel electrophoresis.

the role of TAM in tumor growth is dichotomic and the phenotype of macrophage in vivo reflects both anti-tumor and pro-tumor characteristics of TAM (13).

The process of macrophage activation and differentiation has been discussed based on two different categories. That is, M1 type macrophages respond to lipopolysaccharide and IFN $\gamma$ (classical activation), and M2 type macrophages respond to glucocorticoid, IL-4, IL-10, and IL-13 (alternative activation) (14). In terms of TAM, Mantovani et al claimed TAM would be categorized into M2-polarized cells (15). Indeed, M2 polarization of TAM assists tumor growth, or inhibits anti-tumor immune response (16), indicating that in the balance pro- and anti-tumor characteristics of TAM tend to emphasize pro-tumor. However, in a recent study, TAM unexpectedly expressed chemokines induced by IFN $\gamma$ not only M2 type cytokines (17). Therefore, it is important to explore the phenotype of macrophage within the tumor environment in detail.

In the present study, in order to investigate the state of monocyte-derived cells in the central nervous system (CNS) tumors, we initially tried to determine whether $\mathrm{CD} 11 \mathrm{~b}^{+}$tumor infiltrating cells were macrophages or microglia, a distinction complicated by the fact that there are two populations of
A
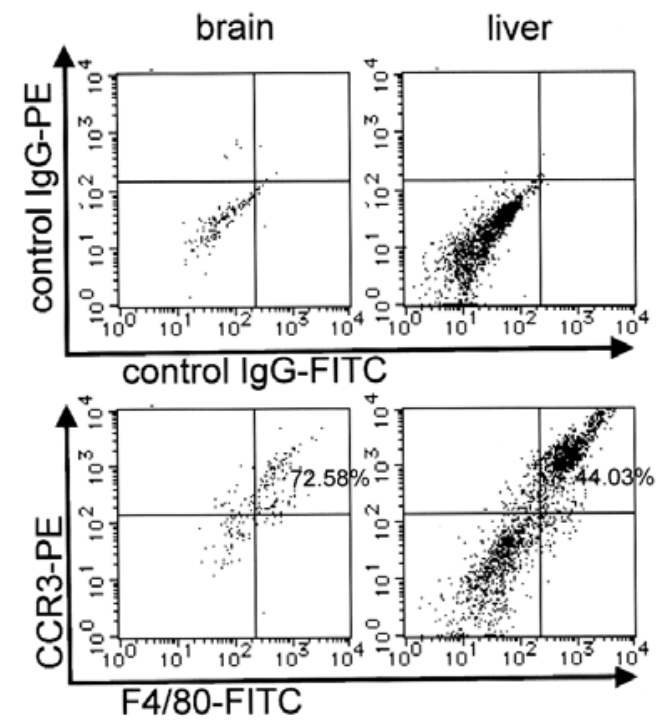

B


intracranial
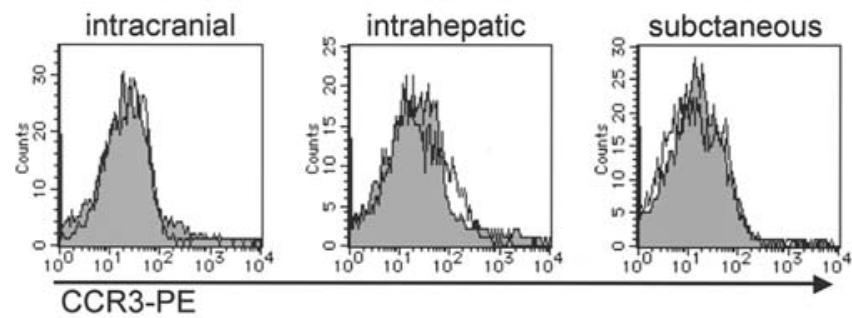

Figure 7. Flow cytometric analysis of CCR3 expression on CD11 $\mathrm{b}^{+}$cells recovered from normal brain or liver (A), and CCR3 and CD45 expression on $\mathrm{CD}_{11 b^{+}}$tumor infiltrating cells recovered at day 14 after intracranial tumor inoculation of GL261mock (B). Representative data of 2 different experiments are shown.

CD11 $\mathrm{b}^{+}$cells in the CNS (18). Since CCR3 is expressed on microglia and Kupffer cells $(19,20)$ and CD45 is highly expressed on macrophages but expressed less briskly on microglia (20), in order to identify the monocyte-derived cells in CNS tumors we examined CD11 $\mathrm{b}^{+}$tumor infiltrating cells for expression of CCR3 and CD45. As shown in Fig. 7A and $\mathrm{B}$, resident microglia and Kupffer cells (both F4/80 expressed CCR3. However, the majority of $\mathrm{CD} 11 \mathrm{~b}^{+}$tumor infiltrating cells do not express CCR3 but are CD45 $5^{\text {high }}$. This suggests that $\mathrm{CD} 11 \mathrm{~b}^{+}$cells which infiltrate CNS tumors are TAM, not microglia. Moreover, we clarified that IL-2 does not influence the composition of TAM and microglia infiltration into the CNS inoculated tumor tissue.

We further characterized the status of TAM in our models. According to the analysis shown in Fig. 6, the activation status of TAM is predominantly influenced by the tumor cells themselves but not the organs inoculated because TAM recovered from any organ developing GL261 tumor express 
A
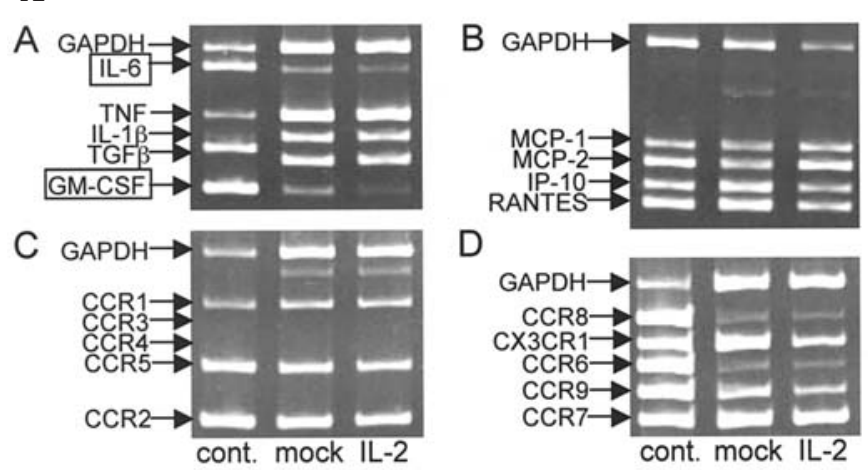

B


Figure 8. (A) Multiple PCR analysis of cytokine, chemokine, and chemokine receptors for $\mathrm{CD} 11 \mathrm{~b}^{+}$tumor infiltrating cells recovered from intracranially inoculated GL261 mock or GL261IL-2. The conditions of analysis were the same as in Fig. 6. (B) Immunofluorochemical analysis of GL261IL-2 inoculated brain tissue. CD11b+ cells were stained with FITC conjugated anti-CD11b antibody (green), and CCR3 antigen was stained with PE-conjugated anti-CCR3 antibody (orange) on the same slide. Each fluorescent image was captured separately and merged using the manufacturer's software $\left(\mathrm{QFISH}{ }^{\circledR}\right)$.

IL-6, GM-CSF, while these cytokines were not detected in the TAM recovered from MCA38. Our data show that TAM isolated from MCA38 tumors are not polarized into either
M1 or M2 macrophages. In contrast, TAM isolated from GL261 tumors are activated and polarized into both M1 and M2 macrophages indicated by expression of both IL-6 (M2) and GM-CSF (M1) (21). Our data suggests that it is difficult to definitively categorize TAM into strict M1 and M2 phenotypes. We propose that polarization and activation of TAM is predominately influenced by the environment provided by individual tumor types.

We would like to consider why TNF blocking showed a differential outcome of tumor growth dependent on the tumor type. One possible explanation concerns the difference in sensitivity to TNF in each tumor type (Fig. 2A). For the case of GL261 glioma, TAM cell surface TNF is hypothesized to be responsible for induction of tumor cell death because secreted TNF was undetectable and IFN $\gamma$ augmented enhancement of TNF receptor expression was observed (Table II and Fig. 2B). We previously reported that the cell surface form of TNF, and not the secreted form, induced $\mathrm{CD}^{+} \mathrm{T}$-cell apoptosis mediated by nitric oxide (11). In addition, TNF [as well as IFN $\gamma$, GMCSF, and IL-3 $(22,23)]$, is involved in priming of macrophagemediated cytotoxicity (24) and can also kill directly (25). In addition, we reported previously that IFN $\gamma$ was secreted not only from $\mathrm{T}$-cell population but also TAM population, and enhanced secretion of IFN $\gamma$ from TAM was observed especially in IL-2-modified tumor environment (26). Therefore, our data suggest that TNF could participate in induction of macrophage-mediated cell killing through IFN $\gamma$ augmented enhancement of TNF receptor expression.

In consideration of why robust infiltration of $\mathrm{CD}^{+} \mathrm{TIL}$ does not correlate with tumor size in GL261IL-2/sTNFRII we note the work of Sica et al who described the mechanism of M1 and M2 differentiation from monocytes and also the function of M2-polarized TAM. They suggest that M2polarized TAM induce anergy in naïve T-cells, activate Th2 cells and inhibit Th1 effectors indirectly through Th2 cells, suppress immune response through activation of regulatory T-cells, and inhibit maturation of tumor-associated dendritic cells (21). The authors also consider that TNF (as well as IL-1, IL-12, CXCL9, and CXCL10) produced from M1polarized macrophage could participate in tumor suppression (21). In our experiments, TAM recovered from GL261 and MCA38 both express TNF and IL-1b (Fig. 6), while these cells expressed M2-polarized cell derived cytokines: IL-10 and TGF $\beta$ in both tumor models, and IL-6 (21) in GL261 tumors. Those observations could mean blocking of the M1expressed TNF (through sTNFRII expression in tumors) may tilt the M1/M2 balance in favor of the M2 phenotype. As shown in Fig. 4, the number of TAM infiltrated at the tumor site of GL261IL-2/sTNFRII statistically increased in comparison to GL261mock tumors. From these data, we speculate that the M2 dominant phenotype (due to TNF blocking) induces inhibition of tumor immune response leading to more aggressive tumor growth; data in Fig. 1 are compatible with that notion.

In conclusion, we show that immunotherapy for different tumor cell types gave rise to different outcomes. TNF shows an additional effect on glioma immunotherapy, while TNF shows a contradictory effect to adenocarcinoma. Therefore, we suggest that the characteristics of a given tumor should be determined precisely before patient immunotherapy. 


\section{Acknowledgements}

This study was supported, in part, by Grant-in-Aid for Scientific Research (Grant 16591437, and 18390393) from Japan Society for the Promotion of Science to Dr M. Saio.

\section{References}

1. Lichtor T and Glick RP: Cytokine immuno-gene therapy for treatment of brain tumors. J Neurooncol 65: 247-259, 2003.

2. Glick RP, Lichtor T, de Zoeten E, Deshmukh P and Cohen EP: Prolongation of survival of mice with glioma treated with semiallogeneic fibroblasts secreting interleukin-2. Neurosurgery 45 : 867-874, 1999

3. Wood GW, Holladay FP, Turner T, Wang YY and Chiga M: A pilot study of autologous cancer cell vaccination and cellular immunotherapy using anti-CD3 stimulated lymphocytes in patients with recurrent grade III/IV astrocytoma. J Neurooncol 48: 113-120, 2000

4. Jeffes EW III, Beamer YB, Jacques S, et al: Therapy of recurrent high grade gliomas with surgery, and autologous mitogen activated IL-2 stimulated killer (MAK) lymphocytes: I. Enhancement of MAK lytic activity and cytokine production by PHA and clinical use of PHA. J Neurooncol 15: 141-155, 1993.

5. Merchant RE, Grant AJ, Merchant LH and Young HF: Adoptive immunotherapy for recurrent glioblastoma multiforme using lymphokine activated killer cells and recombinant interleukin-2. Cancer 62: 665-671, 1988

6. Lewis CE and Pollard JW: Distinct role of macrophages in different tumor microenvironments. Cancer Res 66: 605-612, 2006.

7. Niedbala MJ: Cytokine regulation of endothelial cell extracellular proteolysis. Agents Actions Suppl 42: 179-193, 1993.

8. Ware CF, Van Arsdale S and Van Arsdale TL: Apoptosis mediated by the TNF-related cytokine and receptor families. J Cell Biochem 60: 47-55, 1996.

9. So T, Lee SW and Croft M: Tumor necrosis factor/tumor necrosis factor receptor family members that positively regulate immunity. Int J Hematol 83: 1-11, 2006.

10. Wallach D, Varfolomeev EE, Malinin NL, Goltsev YV, Kovalenko AV and Boldin MP: Tumor necrosis factor receptor and Fas signaling mechanisms. Annu Rev Immunol 17: 331-367, 1999.

11. Saio M, Radoja S, Marino M and Frey AB: Tumor-infiltrating macrophages induce apoptosis in activated CD8(+) T cells by a mechanism requiring cell contact and mediated by both the cellassociated form of TNF and nitric oxide. J Immunol 167: 5583-5593, 2001

12. Balkwill F and Mantovani A: Inflammation and cancer: back to Virchow? Lancet 357: 539-545, 2001.

13. Mantovani A, Bottazzi B, Colotta F, Sozzani S and Ruco L: The origin and function of tumor-associated macrophages. Immunol Today 13: 265-270, 1992.
14. Goerdt S and Orfanos CE: Other functions, other genes: alternative activation of antigen-presenting cells. Immunity 10 137-142, 1999.

15. Mantovani A, Sozzani S, Locati M, Allavena P and Sica A: Macrophage polarization: tumor-associated macrophages as a paradigm for polarized M2 mononuclear phagocytes. Trends Immunol 23: 549-555, 2002.

16. Sinha P, Clements VK and Ostrand-Rosenberg S: Interleukin13-regulated M2 macrophages in combination with myeloid suppressor cells block immune surveillance against metastasis. Cancer Res 65: 11743-11751, 2005.

17. Biswas SK, Gangi L, Paul S, et al: A distinct and unique transcriptional program expressed by tumor-associated macrophages (defective NF-kappaB and enhanced IRF-3/STAT1 activation). Blood 107: 2112-2122, 2006

18. Guillemin GJ, and Brew BJ: Microglia, macrophages, perivascular macrophages, and pericytes: a review of function and identification. J Leukoc Biol 75: 388-397, 2004.

19. Goddard S, Williams A, Morland C, Qin S, Gladue R, Hubscher SG and Adams DH: Differential expression of chemokines and chemokine receptors shapes the inflammatory response in rejecting human liver transplants. Transplantation 72: 1957-1967, 2001

20. Havenith CE, Askew D and Walker WS: Mouse resident microglia: isolation and characterization of immunoregulatory properties with naive $\mathrm{CD}^{+}$and $\mathrm{CD} 8^{+}$T-cells. Glia 22: 348-359, 1998.

21. Sica A, Schioppa T, Mantovani A and Allavena P: Tumourassociated macrophages are a distinct M2 polarised population promoting tumour progression: potential targets of anti-cancer therapy. Eur J Cancer 42: 717-727, 2006.

22. Pace JL, Russell SW, Torres BA, Johnson HM and Gray PW: Recombinant mouse gamma interferon induces the priming step in macrophage activation for tumor cell killing. J Immunol 130: 2011-2013, 1983

23. Young DA, Lowe LD and Clark SC: Comparison of the effects of IL-3, granulocyte-macrophage colony-stimulating factor, and macrophage colony-stimulating factor in supporting monocyte differentiation in culture. Analysis of macrophage antibodydependent cellular cytotoxicity. J Immunol 145: 607-615, 1990.

24. Hori K, Ehrke MJ, Mace K, Maccubbin D, Doyle MJ, Otsuka Y and Mihich E: Effect of recombinant human tumor necrosis factor on the induction of murine macrophage tumoricidal activity. Cancer Res 47: 2793-2798, 1987.

25. Feinman R, Henriksen-DeStefano D, Tsujimoto M and Vilcek J: Tumor necrosis factor is an important mediator of tumor cell killing by human monocytes. J Immunol 138: 635-640, 1987.

26. Ouyang GF, Saio M, Suwa T, et al: Interleukin-2 augmented activation of tumor associated macrophage plays the main role in MHC class I in vivo induction in tumor cells that are MHC negative in vitro. Int J Oncol 28: 1201-1208, 2006. 